\title{
Adopting workload-based staffing norms at public sector health facilities in Bangladesh: evidence from two districts
}

\author{
Md Nuruzzaman ${ }^{1 *} \mathbb{D}$, Tomas Zapata ${ }^{2}$, Valeria De Oliveira Cruz ${ }^{3}$, Sabina Alam4, \\ Samiun Nazrin Bente Kamal Tune ${ }^{5}$ and Taufique Joarder ${ }^{6}$
}

\begin{abstract}
Background: Bangladesh's Health system is characterized by severe shortage and unequitable distribution of the formally trained health workforce. In this context, government of Bangladesh uses fixed staffing norms for its health facilities. These norms do not always reflect the actual requirement in reality. This study was conducted in public sector health facilities in two selected districts to assess the existing staffing norms with the purpose of adopting better norms and a more efficient utilization of the existing workforce.
\end{abstract}

Methods: To carry out this assessment, WHO's Workload Indicators of Staffing Need (WISN) method was applied. Selection of the two districts out of 64 and a total of 24 health facilities were made in consultation with the formally established steering committee of the Ministry of Health. Health facilities, which were performing well in serving the patients during 2016-2017, were selected. This assessment examined staffing requirement of 20 staff categories.

Results: Based on the computer-generated WISN results, most of the staff categories were found to have a workload pressure of Very High (seven out of 20 staff categories), followed by Extremely High (five staff categories). Two staff categories had high, three had moderately high, two normal, and one low workload. Nurses were found to be predominantly occupied with support activities (50-60\% of working time), instead of actual nursing care. Regarding vacancy, if all the vacant posts were filled, understandably, the workload would reduce, but not yet sufficient to meet the existing staff requirements such as consultants, general physicians and nurses at the district and sub-district/ upazila-based hospitals.

Conclusion: The existing staffing norms fall short of the WISN staffing requirement. The results provide evidence to prompt a revisit of the staffing policies and adopt workload-based norms. This can be supplemented by reviewing the scope of practice of the staff categories in their respective health facilities. In the short term, government might consider redistributing existing workforce as per workload. In the long term, revision of staffing norms is needed to provide quality health services for all.

Keywords: Workload, Bangladesh, Staffing norms, Human resources for health

*Correspondence: nuruzzamanm@who.int

${ }^{1}$ Human Resources for Health, WHO Bangladesh, Dhaka, Bangladesh

Full list of author information is available at the end of the article

\section{Background}

Bangladesh was identified as one of the severe health workforce shortage countries by the World Health Organization (WHO) in the World Health Report 2006 [1]. This was because the country had a density of doctors, nurses and midwives of 5.8 per 10,000 population in original author(s) and the source, provide a link to the Creative Commons licence, and indicate if changes were made. The images or other third party material in this article are included in the article's Creative Commons licence, unless indicated otherwise in a credit line to the material. If material is not included in the article's Creative Commons licence and your intended use is not permitted by statutory regulation or exceeds the permitted use, you will need to obtain permission directly from the copyright holder. To view a copy of this licence, visit http://creativecommons.org/licenses/by/4.0/. The Creative Commons Public Domain Dedication waiver (http://creativeco mmons.org/publicdomain/zero/1.0/) applies to the data made available in this article, unless otherwise stated in a credit line to the data. 
2006 [2]. The WHO Global Strategy on Human Resources for Health: Workforce 2030 estimated an indicative requirement of the threshold density of 44.5 doctors, nurses and midwives per 10,000 population to achieve SDGs by 2030 [3]. According to the latest WHO SouthEast Asia Regional Office assessment of health workforce in SEAR countries, Bangladesh has reached a density of doctor, nurse and midwife of 9.9 [4]. This indicates that the country has a chronic shortage of the number of formally trained of health workforce. Besides, health services in Bangladesh are crippled by several other health workforce challenges such as maldistribution between rural and urban areas, lack of career development opportunities, weak knowledge base, high vacancy rate in the public sector and poor working conditions $[5,6]$.

In this context, the Government of Bangladesh (GOB) adopted the Essential Services Package (ESP) as a strategy in 2016-2017 towards achieving Universal Health Coverage [7]. ESP was designed to deliver health services at the facilities located at district level and below to household level under the Ministry of Health and Family Welfare (MOHFW). Now, to guide health workforce recruitment and salary budget and to determine staffing level at those public-sector health facilities, MOHFW uses the fixed staffing norms established in 2008, approved by the Ministry of Public Administration [8]. These staffing norms vary according to the health facility type and availability of healthcare services. There is little scope to account for workload variation of staffs, or facility-specific outputs, leading to inefficiency. The fixed staffing norms adopted by the MOHFW are based on 'bed number' and 'number of population to serve' and these are not responsive to the factors like population growth, geographical location and climate change, physical facilities availability, changing pattern of the disease burden and patient preferences [9].

In this regard, the Bangladesh Health Workforce Strategy-2015 urges determination of health workforce need, and project demand up to 2030 as per level of care (i.e., primary, secondary and tertiary levels) [10]. To do such, the strategy recommends consideration of workload in determining the staffing needs of different health facilities.

In order to assist Member States to assess workload of the staff, the WHO developed the "Workload Indicators of Staffing Need (WISN)" in 1998 and introduced its computerized version in 2010 [11, 12]. This article describes the application of the WISN method in two selected districts in Bangladesh and how staffing norms can be reshaped in Bangladesh. The main purpose is to explain the limitations of the currently practiced staffing norms in different health facilities in a district health system and to generate evidence to inform policy for appropriate staffing decision and staff deployment for more efficient use of the scarce human resources.

\section{Methods}

This study was initiated by Human Resources Development (HRD) Unit, MOHFW with reference to the Bangladesh Health Workforce Strategy-2015. This initiative was technically supported by the World Health Organization (WHO) Bangladesh and data collection and analysis was carried out by the BRAC James P Grant School of Public Health, BRAC University. A national-level WISN training of trainers including district managers from the two pilot districts was conducted by WHO in November 2016.

In order to assess the current workload of the existing staff at their respective health facilities during the study period, WHO's WISN manual was adopted and followed. According to this manual, there are eight steps to apply the WISN method: (1) determining priority cadres and health facility types; (2) estimating available working time; (3) defining workload components; (4) setting activity standards; (5) establishing standard workloads; (6) calculating allowance factors; (7) determining staff requirement based on WISN, and (8) analyzing and interpreting WISN results. All those steps were carried out in consultation and collaboration with the Steering Committee (SC) established at national level, Technical Taskforce (TT) and Expert Working Groups (EWGs). The SC was established by the MOHFW, GOB and provided overall guidance to the whole initiative. The TT led the implementation of the project and EWGs were formed to provide expert opinion on determination of service activity standard based on ESP components.

This assessment was conducted in two selected districts out of 64 in Bangladesh during July to November 2017. Table 1 shows composition of district health system, its type, catchment population, major essential services delivered, key staff and staffing norms with reference to the 2008 staffing standard of the GOB.

The bulk of primary health care services are delivered through Community Clinics (CCs), Union Sub-Centers (USC), Union Health and Family Welfare Centers (UHFWC) and Upazila Health Complexes (UpHCs). District-based general hospitals provide secondary-level health care and also serves as the referral point for the primary level health facilities. The MOHFW has the primary responsibility for human resource investments of all primary and secondary-level health facilities, whereas the Ministry of Public Administration serves as the approving authority on HR matters (e.g., recruitment rules, post creations, job descriptions, table of organizations and equipment, etc.) on behalf of the government [14]. 
Table 1 District healthcare system of Bangladesh [13]

\begin{tabular}{|c|c|c|c|}
\hline Type of health facility & $\begin{array}{l}\text { Location (catchment population } \\
\text { size) }\end{array}$ & Major ESP delivered & $\begin{array}{l}\text { Staffing norms and key staff } \\
\text { numbers with reference to the } \\
2008 \text { staffing standard }\end{array}$ \\
\hline $\begin{array}{l}\text { District-based General Hospital } \\
\text { (250-bed) }\end{array}$ & District town $(2,500,000)$ & $\begin{array}{l}\text { In-patient and out-patient services } \\
\text { Maternal and child health care } \\
\text { Orthopedic services } \\
\text { Minor to moderate level surgical } \\
\text { services } \\
\text { Common consultant/specialized } \\
\text { services } \\
\text { Medical imaging and laboratory } \\
\text { services }\end{array}$ & $\begin{array}{l}\text { Staffing norms is based on the total } \\
\text { bed size of the hospital } \\
\text { Consultant ( } 22) \\
\text { Medical Officers/General Physicians } \\
\text { (23) } \\
\text { Nursing Staff (80) }\end{array}$ \\
\hline $\begin{array}{l}\text { Maternal and Child Welfare Center } \\
\text { (10-bed hospital) }\end{array}$ & District town $(2,500,000)$ & $\begin{array}{l}\text { Maternal and child health services } \\
\text { including normal delivery and } \\
\text { caesarian section } \\
\text { Family planning services } \\
\text { In-patient and out-patient services }\end{array}$ & $\begin{array}{l}\text { Staffing norms is based on the total } \\
\text { bed size } \\
\text { Medical Officers (MO) (2) } \\
\text { Family Welfare Visitor (2) }\end{array}$ \\
\hline $\begin{array}{l}\text { Upazila or Sub-District Health Com- } \\
\text { plex (50-bed hospital) }\end{array}$ & $\begin{array}{l}\text { Upazila/Sub-District town }(250,000- \\
400,000)\end{array}$ & $\begin{array}{l}\text { In-patient and out-patient services } \\
\text { Maternal and child health care } \\
\text { Orthopedic cares } \\
\text { Minor surgical services } \\
\text { Major consultant/ specialized } \\
\text { services }\end{array}$ & $\begin{array}{l}\text { Staffing norms based on the total } \\
\text { bed numbers } \\
\text { Consultant (10) } \\
\text { Medical officer (7) } \\
\text { Nursing Staff (15) } \\
\text { Sub-Assistant Community Medical } \\
\text { Officer (1) }\end{array}$ \\
\hline $\begin{array}{l}\text { Union Health and Family Welfare } \\
\text { Center (only outdoor) }\end{array}$ & Union-level- rural periphery $(40,000)$ & $\begin{array}{l}\text { Out-patient services } \\
\text { Maternal and child health care } \\
\text { Family planning services }\end{array}$ & $\begin{array}{l}\text { Ad hoc norms } \\
\text { Family Welfare Visitor (1) } \\
\text { Sub-Assistant Community Medical } \\
\text { Officer (1) }\end{array}$ \\
\hline $\begin{array}{l}\text { Union Sub-Center } \\
\text { (only outdoor) }\end{array}$ & Union-level- rural periphery $(40,000)$ & $\begin{array}{l}\text { Out-patient services } \\
\text { Maternal and child health care }\end{array}$ & $\begin{array}{l}\text { Ad hoc norms } \\
\text { Medical officer (1) } \\
\text { Sub-Assistant Community Medical } \\
\text { Officer (1) }\end{array}$ \\
\hline Community Clinic (only outdoor) & Ward level (6000) & $\begin{array}{l}\text { Out-patient services } \\
\text { Maternal and child health care } \\
\text { Family planning services }\end{array}$ & $\begin{array}{l}\text { Population-based staff norms (i.e., } \\
\text { one staff per } 6000 \text { population) } \\
\text { Community Health Care Provider (1) } \\
\text { Health Assistant (1) } \\
\text { Family Welfare Assistant (1) }\end{array}$ \\
\hline
\end{tabular}

\section{Selection of health workforce categories}

In consultation with the Steering Committee and Technical Taskforce members and taking consideration of similar studies conducted in other countries, the following 20 categories of health workforce were identified from the selected health facilities (Table 2).

\section{Defining workload component}

According to the WHO's WISN manual (2010), there are three workload components, which are: (1) health service activity; (2) support activity, and (3) additional activity. Health service activity refers to all the activities performed by all members of the health workforce categories and for which annual statistics are regularly collected, e.g., antenatal care. Support activity supports the implementation of health service activities. These activities are performed by all members of the health workforce categories, but for which annual statistics are not regularly collected, e.g., monthly report writing. Additional activities are those activities, which are performed only by certain (not all) members of the staff, e.g., supervisory role. Annual statistics are not regularly collected for them.

\section{Study design, sites and sample selection}

Since the WISN method was not in practice in the public sector health facilities in Bangladesh, an exploratory study involving both qualitative and quantitative methods was commissioned. The qualitative methods involved document reviews, key informant interviews (KIIs) with policy level persons (mostly from among steering committee and expert group members, total 20), in-depth interviews (IDIs) with the health workforce (total 87, e.g., physicians, nurses, etc.), and observations.

KII respondents were selected on the principles of purposive sampling [15], supplemented by snowball sampling (i.e., based on the reference or suggestion from the key informants). IDI respondents were selected through purposive sampling, based on the respondent's seniority (assuming better knowledge of 
Table 2 Facility types and staff categories for the WISN study

\begin{tabular}{|c|c|c|}
\hline Type of facility $(N=24)$ & Study sites & Staff category \\
\hline District hospital $(n=2)$ & $\begin{array}{l}\text { Jhenaidah District Hospital (100 bed) and } \\
\text { Moulvibazar 250-bed District Hospital }\end{array}$ & $\begin{array}{l}\text { Consultants (Surgery, Anesthesiology, Obstetrics and } \\
\text { Gynecology, Ear Nose and Throat, Medicine, Pediat- } \\
\text { rics, Cardiology, Orthopedics) } \\
\text { General Physicians (Medical Officer), Emergency } \\
\text { Medical Officer, Resident Medical Officer) } \\
\text { Nursing Staff (Senior Staff Nurse, Nursing Supervisor) }\end{array}$ \\
\hline Maternal and Child Welfare Center $(n=2)$ & Jhenaidah and Moulvibazar & $\begin{array}{l}\text { Medical Officer (MO) } \\
\text { Family Welfare Visitor (FWV) }\end{array}$ \\
\hline Upazila Health Complex (UpHC) $(n=4)$ & $\begin{array}{l}\text { Shailkupa UpHC and Kotchandpur UpHC from } \\
\text { Jhenaidah } \\
\text { Kulaura UpHC, and Sreemangal UpHC from } \\
\text { Moulvibazar }\end{array}$ & $\begin{array}{l}\text { General Physicians, } \\
\text { Nursing Staff (Senior Staff Nurse, Nursing Supervisor) } \\
\text { Sub-Assistant Community Medical Officer (SACMO) }\end{array}$ \\
\hline $\begin{array}{l}\text { Union Sub-Center }(n=4) \text { and Union } \\
\text { Health and Family Welfare Center }(n=4)\end{array}$ & $\begin{array}{l}\text { Jhenaidah: Kacherkhol, Sabdalpur, Moharajpur and } \\
\text { Dudhshar, } \\
\text { From Moulvibazar: Prithempasha, Bhunabir, Chand- } \\
\text { nighat and Ashidron }\end{array}$ & SACMO, FWV \\
\hline Community clinic $(n=8)$ & $\begin{array}{l}\text { From Jhenaidah: Khandakbariya, Kagmari, Kulbaria, } \\
\text { and Korotipara, Sripur, } \\
\text { From Moulvibazar: Igragaon, Dakkhin Chamatkar, } \\
\text { and Akbarpur }\end{array}$ & $\begin{array}{l}\text { Community Health Care Provider } \\
\text { Family Welfare Assistant }\end{array}$ \\
\hline
\end{tabular}

This assessment put focus on the above categories of health workforce as they have been the leading frontline health care providers

the activity standards) and designation (e.g., Medical Doctors, Nursing Supervisors, etc.). Semi-structured guidelines or checklists for document reviews, KIIs, IDIs, and observation were developed and pre-tested in a district-based general hospital near the capital city, Dhaka, before applying for actual data collection. The pre-testing exercise was followed by the training of the data collectors.

The Steering Committee selected the two districts based on selected performance indicators, i.e., low maternal mortality ratio, low child mortality rate and low morbidity rate prevailing in those regions. According to the Health Bulletin 2016, these two districts turned out as the good performing ones, based on the indicators mentioned above [16]. Among the two districts, Jhenaidah is located in south-western part of Bangladesh, under Khulna Division; while Moulvibazar is located in north-eastern part of Bangladesh, under Sylhet Division.

From each district, based on the guidance from steering committee, one District Hospital (DH), one Maternal and Child Welfare Center (MCWC), two UpHCs, two USCs, two UHFWCs, and four CCs were included in this study (Table 2).

The quantitative method involved a time-motion study with all consenting staff during the study period. Each staff was observed twice for a 45-min time, during the first and second half of the day, to minimize the bias due to patient load at different parts of the day. The time-motion data were used only to guide the activity standards proposed in the IDIs.

\section{Data collection strategy}

A central WISN technical taskforce was established and they were technically assisted by the lead author. The principal investigator formed two data collection teams, who were led by field supervisors and sent to the two districts, respectively. Two assigned Investigators were guiding and monitoring them for a sound data collection process. In order to ensure data quality, the principal investigator, co-investigators, WHO team consisting of national and international technical experts, and representatives from the MOHFW conducted field visits to each study district and the health facilities therein.

\section{Data management and analysis}

Based on the WISN manual, the first analytic step was to estimate available working time (AWT) of the staff. This is the time a health worker has available in one year to do his or her work, taking into account authorized and unauthorized absences [11]. For all categories of staff, a uniform number of weeks per year (52 weeks), working days in 1 week ( 6 days), possible working days in 1 year $(52 \times 6=312$ days $)$ were estimated. Next, absent days, such as public holidays (20 days), earned leave (average for each staff category, based on Health Management Information System data), and casual leave (20 days) were deducted to obtain the annual working time in days. Multiplying this with daily working hours ( $6 \mathrm{~h}$ per day), annual working time was calculated in hours.

Based on the current number of staff posted to their respective health facilities, both the difference (current number of staff-required number of staff by WISN), 
and the ratio (current number of staff/required number of staff by WISN) were calculated. The WISN difference indicates whether the health facilities are relatively understaffed (i.e., when the WISN Difference is negative), overstaffed (i.e., when the WISN difference is positive), or balanced (i.e., when the WISN difference is zero). The WISN ratio indicates whether the staff are experiencing high workload (i.e., when the WISN ratio is lower than one), low workload (i.e., when the WISN ratio is higher than one), or normal workload (i.e., when the WISN ratio is equal to one). For this calculation, the current number of staff of each facility was obtained from the existing human resource information system and later was verified with the head of the facility and its payroll system.

For descriptive purposes, the workload pressure is categorized as Extremely High (WISN ratio between 0.10 and 0.29 ), Very High (WISN ratio between 0.30 and 0.49), High (WISN ratio between 0.50 and 0.69), Moderately High (WISN ratio between 0.70 and 0.89 ), Normal (WISN ratio between 0.90 and 1.19), and Low (WISN ratio greater than or equal to 1.20) [11].

\section{Results}

General WISN findings across district, upazila (sub-district), union and community levels

At an aggregate level (i.e., considering the average required number and WISN ratio across the same types of health facilities), with reference to Table 3, a good number of the staff categories were found to have a workload pressure of Very High (seven out of 20 staff categories), followed by Extremely High (five staff categories). Two staff categories had high, three had moderately high, two normal, and one low workload (Table 3). The highest workload was observed among the following staff categories: Consultants of Medicine (WISN ratio 0.16), Pediatrics (WISN ratio 0.20), Anesthesiology (WISN ratio 0.20 ), Obstetrics and Gynecology (WISN ratio 0.25 ), and Surgery (WISN ratio 0.28 ) (Table 3 ).

In general, the highest number of health workforce is required (discounting the existing staff) for DH Nursing Staff (135.92 on an average), followed by DH General Physicians (35.10 on an average), and UpHC Nursing Staff (18.86) (Table 3).

Highest shortage (i.e., deducting required number from current number of staff) is observed among the Consultant (Obstetrics and Gynecology) category of Jhenaidah District Hospital (Difference - 14.63), followed by

Table 3 Analysis of WISN results at aggregate level (average required number and WISN ratio across same types of health facilities)

\begin{tabular}{|c|c|c|c|c|c|}
\hline Staff category & $\begin{array}{l}\text { Required staff } \\
\text { to cope with the } \\
\text { workload }\end{array}$ & $\begin{array}{l}\text { Average } \\
\text { number of } \\
\text { existing staff }\end{array}$ & Deficit of staff & $\begin{array}{l}\text { Average } \\
\text { WISN } \\
\text { ratio }\end{array}$ & Workload pressure \\
\hline Consultant (Surgery) & 7.42 & 2.0 & 5.42 & 0.28 & Extremely high \\
\hline Consultant (Anesthesiology) & 4.98 & 1.0 & 3.98 & 0.2 & Extremely high \\
\hline Consultant (Obstetrics and gynecology) & 11.0 & 2.0 & 9 & 0.25 & Extremely high \\
\hline Consultant (Orthopedics) & 5.04 & 2.0 & 3.04 & 0.41 & Very high \\
\hline Consultant (Ear, Nose and Throat) & 2.82 & 1.5 & 1.32 & 0.67 & High \\
\hline Consultant (Medicine) & 12.0 & 2.0 & 10 & 0.16 & Extremely high \\
\hline Consultant (Pediatrics) & 7.64 & 1.5 & 6.14 & 0.2 & Extremely high \\
\hline Consultant (Cardiology) & 4.21 & 1.5 & 2.71 & 0.35 & Very high \\
\hline District Hospital General Physician & 35.10 & 11.0 & 24.1 & 0.32 & Very high \\
\hline District Hospital Nurse & 135.92 & 66.0 & 69.92 & 0.49 & Very high \\
\hline $\begin{array}{l}\text { Maternal and Child Welfare Center (MCWC)_-General } \\
\text { Physician }\end{array}$ & 4.22 & 2.0 & 2.22 & 0.48 & Very high \\
\hline MCWC Family Welfare Visitor (FWV) & 5.8 & 4.5 & 1.3 & 0.81 & Moderately high \\
\hline Upazila Health Complex (UpHC) General Physician & 10.59 & 4.5 & 6.09 & 0.43 & Very high \\
\hline UpHC Nurse & 18.86 & 12.7 & 6.11 & 0.69 & High \\
\hline UpHC SACMO* & 10.43 & 7.75 & 2.68 & 0.75 & Moderately high \\
\hline Union Sub-Center SACMO* & 2.33 & 1.00 & 1.33 & 0.49 & Very high \\
\hline UHFWC $^{* *}$ SACMO* & 1.04 & 1.00 & 0.04 & 1.29 & Low \\
\hline UHFWC FWV & 1.18 & 1.00 & 0.18 & 0.85 & Moderately high \\
\hline Community Clinic_-Community healthcare provider & 1.34 & 1.0 & 0.34 & 0.92 & Normal \\
\hline Community Clinic_-Family Welfare Assistant & 0.96 & 1.0 & -0.04 & 1.1 & Normal \\
\hline
\end{tabular}

*SACMO Sub-Assistant Community Medical officer, UHFWC **Union Health and Family Welfare Center 
Consultant (Medicine) in both the District Hospital (Difference - 11.07 in Jhenaidah, and 12.94 in Moulvibazar). Although workload pressure is relatively lower (WISN Ratio 0.49 and 0.48 in Jhenaidah and Moulvibazar, respectively), the shortage of District Hospital Nursing Staff (i.e., Senior Staff Nurse and Nursing Supervisor) is the highest (WISN Difference - 64.86 and -74.98 in Jhenaidah and Moulvibazar, respectively) among all the staff categories. This is followed by that among the General Physicians in District Hospitals (WISN Difference -23.29 and -24.90 in Jhenaidah and Moulvibazar, respectively).

Normal or low workload is very uncommon, except for UHFWC SACMOs, CC CHCPs and CC FWAs (average WISN ratio 1.29, 0.92, and 1.1, respectively). Excess staff and low workload pressure is observed particularly among CHCPs in four CCs (out of eight): Khandakbaria (WISN Difference 0.11 and ratio 1.12), Kulbaria (WISN difference 0.23 and ratio 1.37), Dakkhin Chamatkar (WISN difference 0.12 and ratio 1.14), and Akbarpur (WISN difference 0.14 and ratio 1.16); and FWAs in four CCs (out of five): Khandakbaria (WISN difference 0.25 and ratio 1.33), Korotipara (WISN difference 0.15 and ratio 1.18), Sripur (WISN difference 0.04 and ratio 1.04), and Dakkhin Chamatkar (WISN difference 0.21 and ratio 1.27).

\section{Workload components-wise workload pressures}

Physicians of Jhenaidah and Moulvibazar District hospitals and Upazila Health Complexes (UpHCs) spend $27-29 \%$ of their AWT on support and additional activities like meetings, medico-legal cases, national day celebration, supervision of clinical staffs, etc. Nursing staffs of Jhenaidah and Moulvibazar District hospital and Upazila level spend more than half (53-62\%) of the AWT on support services and additional services, such as making patient beds, linen management, maintenance of stock register, cleaning supervision, etc. They provide health services only on $38-47 \%$ of their AWT time (Fig. 1).

\section{Change of workload if vacancies are filled against the number of sanctioned posts}

"Sanctioned post" refers to the post and its designation to which staff is assigned in a particular public-sector health facility as per the national staffing norms. The post and its number are approved by the MOPA and Ministry of Finance. Each public sector health facility has its own organogram and the organogram reflects the number of sanctioned posts including designation. If the vacant posts are filled, understandably, the workload is reduced. However, only filling up the vacant posts are not enough in the case of some of the staff categories, such as general physicians and nurses at the DH (Table 4).

The WISN ratios were calculated based on the workload of the current number of staff. These ratios help to determine the most appropriate minimum staffing for each level of health facility to provide the expected range of services. Table 4 compares the WISN-based staff requirement with the existing staffing norms. For example, during the study period, Jhenaidah district hospital had only 11 general physicians, but workload-based requirement was 34 . Within the existing staffing norms, government could recruit only 17 physicians [8]. Same scenarios were observed for both doctor and nurse categories in all DHs and UpHCs.

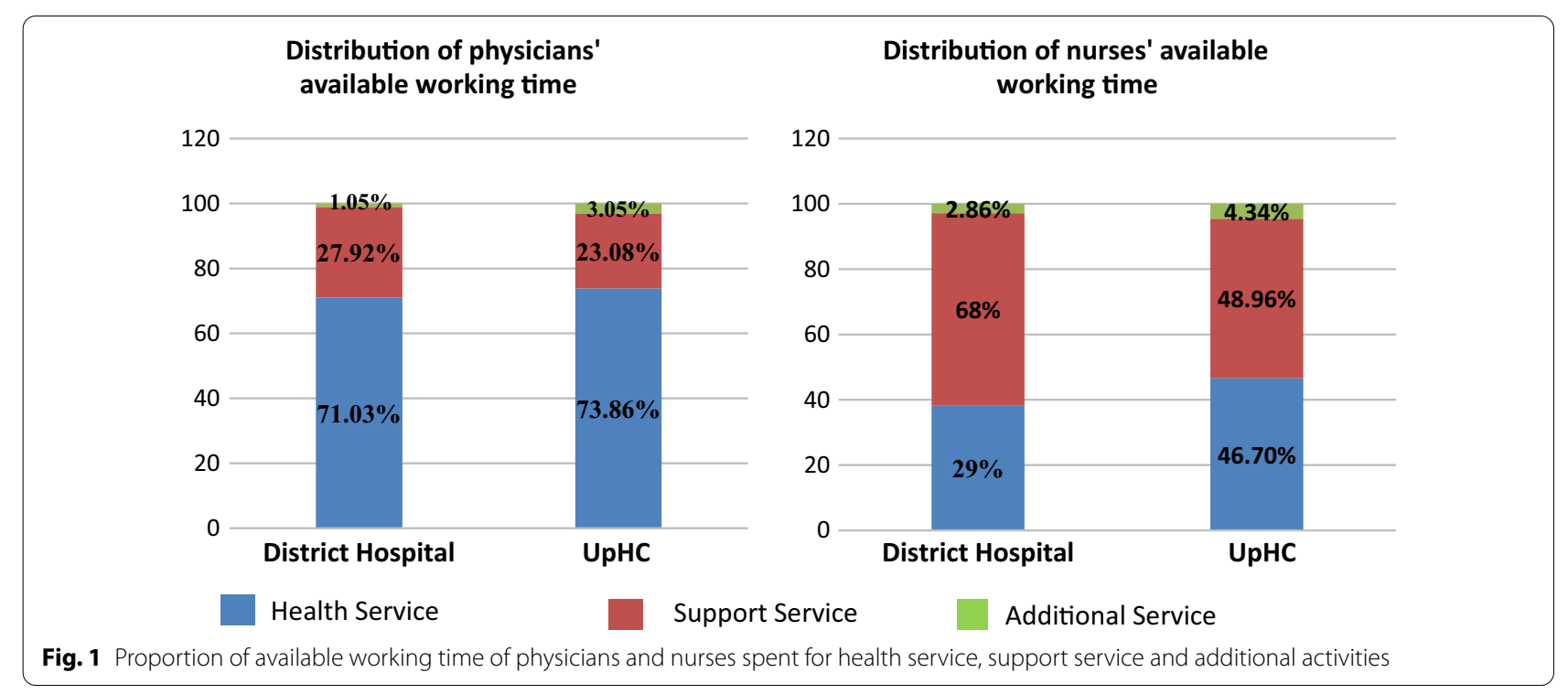


Table 4 Change of workload if vacancies of physician and nursing posts are filled

\begin{tabular}{|c|c|c|c|c|c|c|}
\hline Health facility & Staff category & $\begin{array}{l}\text { Current } \\
\text { number of } \\
\text { staff }\end{array}$ & $\begin{array}{l}\text { Required number, } \\
\text { based on WISN }\end{array}$ & WISN ratio & $\begin{array}{l}\text { Sanctioned } \\
\text { number of staff } \\
{[8]}\end{array}$ & $\begin{array}{l}\text { WISN ratio as per } \\
\text { sanctioned number } \\
\text { of staff }\end{array}$ \\
\hline \multirow[t]{2}{*}{ Jhenaidah DH } & General Physician & 11 & 34.29 & 0.32 & 17 & 0.50 \\
\hline & Nursing Staff & 62 & 126.86 & 0.49 & 80 & 0.63 \\
\hline \multirow[t]{2}{*}{ Moulvibazar DH } & General Physician & 11 & 35.9 & 0.31 & 22 & 0.61 \\
\hline & Nursing Staff & 70 & 144.98 & 0.48 & 80 & 0.55 \\
\hline \multirow[t]{2}{*}{ Shailkupa UpHC } & General Physician & 4 & 8.14 & 0.49 & 7 & 0.88 \\
\hline & Nursing Staff & 14 & 16.08 & 0.87 & 15 & 0.94 \\
\hline \multirow[t]{2}{*}{ Kotchandpur UpHC } & General Physician & 3 & 10.71 & 0.28 & 7 & 0.64 \\
\hline & Nursing Staff & 15 & 22.8 & 0.66 & 15 & 0.65 \\
\hline \multirow[t]{2}{*}{ Kulaura UpHC } & General Physician & 4 & 12.28 & 0.33 & 7 & 0.58 \\
\hline & Nursing Staff & 10 & 16.08 & 0.62 & 15 & 0.93 \\
\hline \multirow[t]{2}{*}{ Sreemangal UpHC } & General Physician & 7 & 11.23 & 0.62 & 7 & 0.64 \\
\hline & Nursing Staff & 12 & 20.46 & 0.59 & 15 & 0.75 \\
\hline
\end{tabular}

\section{Discussion}

This WISN study results clearly indicate that public sector healthcare providers in Bangladesh, in general, are suffering from a very high workload pressure (seven out of 20 staff categories under study have WISN ratio between 0.30 and 0.49 ). The most overworked staff are the district hospitals consultants (most notably the Medicine, Pediatrics, Anesthesiology, Obstetrics and Gynecology, and Surgery Consultants). This also indicates the highest numbers of staff required are nurses and physicians at both $\mathrm{DH}$ and UpHCs.

Study results also indicate inadequacy of staffing norms in the public sector health facilities due to presence of high workload. Historically, Bangladesh has faced shortage of formally trained health workers. The country has thus been looking for innovative ways to achieve a more efficient use of its qualified health workforce in the health sector-particularly in the context of increased demand for health services, evolving disease management policies and demographic changes [10].

Even in facilities that are considered to be 'well' staffed, their staffing levels are not adequate to provide the full range of services required and to handle the accompanying workload. This clearly demonstrates the need to review the existing staffing norms of public sector health facilities with a view of equitably providing at least the essential service package in the country.

High workload pressure also has serious consequences, namely, fatigue and burnout of service providers, lack of motivation, and compromised quality of care [17]. High workload is, however, not unique to Bangladesh. WISN studies in low- and middle-income countries like Uganda [9], Burkina Faso [18], Iran [19], Kenya [20], and Namibia [21] also identified high workload pressure among their human resources for health.

The high workload of the staff at the district level and below have management implications for the delivery of quality ESP services. For example, due to high number of patients, staff are unable to provide services within the standard amount of time. This might be a coping mechanism of service providers to reach services to the maximum number of patients. The other side of the coin is that service providers may not be optimizing their working time, for example, by not coming on time or not staying the full official duty time. Nevertheless, contact time with the patient is an established predictor of quality of care [22], patient satisfaction [22, 23], and responsiveness [24]. A recent study from Bangladesh showed the outpatient department consultation time in public sector health facilities range from $48 \mathrm{~s}$ to $4.04 \mathrm{~min}$ per patient $[25,26]$, which is also low, as we found in this study. Results from this study are consistent with the findings of a similar WISN study conducted in other two districts in Bangladesh [27].

A culture of workload-based human resource management systems needs to be developed and this could be done through systematic planning and strong monitoring platforms. This might include establishing welldefined roles and responsibilities of the team responsible for WISN application-with clear deliverables, timelines and reporting structures. In Namibia and Uganda, WISN application taskforces directly report to the Permanent Secretary of the Health Ministry. The taskforce should be given adequate authority and autonomy to carry out the implementation.

This WISN study was utilized to facilitate a national policy dialogue on health workforce in April 2019 with 
participation of the most senior officials (Health Secretary and the Director General of health services) of the MOHFW, among others. The results of the study were used to advocate for the review of the current 2008 national staffing norms and for increasing the demand, availability and investment in the health workforce in Bangladesh. The results of this study have been used to support updating the staffing norms of the Table of Organization and Equipment of 50-bed, 250-bed and 500-bed hospitals in Bangladesh [28]. Increasing the investment on and the availability of health workers became even more relevant during the COVID-19 pandemic. Bangladesh went into the COVID-19 pandemic with a high shortage of health workers (especially doctors, nurses and laboratory workforces) and this has been exacerbated during the response to the pandemic by hampering not only the COVID-19 response, but also availability of essential health services [29].

\section{Strengths and limitations}

Major strengths of this study were such as setting activity standard was supported by time-motion study which helped the expert groups to determine context specific activity standard. The study adopted both qualitative and quantitative methods for primary data collection, which complemented each other for bringing data accuracy. Technical inputs received from the WHO's international technical experts, and officials of the MOHFW improved the data quality as they were directly involved in quality checks at the field level.

Despite careful planning and thorough implementation of the assessment, the study team faced some challenges. First, some service statistics data, which were essential for establishing standard workloads, were unavailable (e.g., OPD visits data for the DH Consultants, separate followup antenatal care data below the Upazila level, etc.). Second, the official number of existing staff often did not match with the number of staff the data collection team observed providing services (e.g., SACMOs, though they were posted at Union-level facilities, they were found to provide service at the UpHCs for 3 days a week). These often confused our data collectors and had to deal with these issues and resolved in consultation with respective heads of institutions during data collection.

\section{Recommendations}

The findings of this study have several broad implications that can help guide $\mathrm{HRH}$ investments by the government as well as health and development partners. First, in the short term, reallocation of staff from low workload areas to high workload areas could be affected. For example, in Shailkupa UpHC, there are 15 SACMOs, with an excess supply of almost five. Workload is Low with a WISN ratio of 1.48. Conversely, in nearby Kotchandpur UpHC, there are seven SACMOs, with a shortage of -6.81 . Workload is High with WISN ratio of 0.51. At least five SACMOs from Shailkupa can be reallocated to Kotchandpur to tackle the high workload.

Second, the current scope of work of nurses should be changed to reduce their support services. As evidenced from the WISN results, nurses were the most needed staff, one of the most overloaded, and short in supply. On top of all these, they had been burdened with support activities. If some of their support and additional activities could be shifted to other staff, nurses could devote their time better in nursing care.

Third, task shifting could be adopted as a strategy to reduce consultants' workload. Since the Consultants, especially those of Medicine, Pediatrics, Anesthesiology, Obstetrics and Gynecology, and Surgery were undergoing an extremely high workload pressure, their tasks might be shifted to other staff. General physicians, nurses, and midwives could be engaged in some of the tasks that consultants currently undertake. Since the government is currently developing the midwifery cadre and recruiting them in larger numbers, they might be engaged to perform some of the current functions performed by the Gynecology and Obstetrics Consultants such as conducting ANC, PNC, and new-born care [30].

In the long term, the government of Bangladesh should review and revise the current staffing norms based on health facility workload. Although in some cases, filling up vacant posts can improve the workload situation, in many others this is not much helpful. In district hospitals, even if all sanctioned posts are filled out for consultants, general physicians and nurses, still the WISN ratio would not be normal (i.e., between 0.90 and 1.19). Therefore, policy-makers should review the staffing norms of health facilities based on that facility's workload and make decisions specific to the individual local context. To this front, the WISN method could be an objective tool to show locally appropriate staffing levels and help to achieve a more efficient use of scarce resources, while improving healthcare coverage across the district health system.

\section{Conclusion}

The current staffing norms of public sector health facilities in Bangladesh appear not responsive to actual health needs and demand of the population in the selected districts where the WISN method was applied and likely to be the case in other parts of the country, given its centralized governance structure. A review of the national staffing norms will be critical in reducing shortages of health workers as high workload prevailed already prior to the COVID-19 outbreak. It now has 
become even more pressing, as workload has significantly increased, and more health workers are needed to effectively respond to COVID-19 and to maintain essential health services. With a vision of becoming an upper middle-income country by 2021 and meeting the commitment towards Universal Health Coverage by 2030, Bangladesh needs to optimize its human resources. Such assessments can aid policy and decision-makers in this direction.

\begin{abstract}
Abbreviations
AWT: Available working time; CC: Community clinic; DH: District Hospital; ESP: Essential services package; EWGs: Expert working groups; FWV: Family welfare visitor; GOB: Government of Bangladesh; HRD: Human resources development; HRH: Human resources for health; IDIs: In-depth interviews; Klls: Key informant interviews; MO: Medical officer; MCWC: Maternal and Child Welfare Center; MOHFW: Ministry of Health and Family Welfare; SACMO: Sub-Assistant Community Medical Officer; SC: Steering committee; TT: Technical taskforce; UHFWC: Union Health and Family Welfare Center; UpHC: Upazila Health Complex; USC: Union sub-center; WHO: World Health Organization; WISN: Workload indicators of staffing need.
\end{abstract}

\section{Acknowledgements}

The authors express their gratitude to the World Health Organization Country Office, Bangladesh, for initiating the project, as well as the Ministry of Health and Family Welfare, Bangladesh, for supporting it throughout the study period. We are also thankful to the study participants who consented to participate in the study. We are sincerely thankful to the BRAC James P Grant School of Public Health, BRAC University, for conducting the field work. We also acknowledge Dr Mohammad Mostafa Zaman, Advisor-Research and Publication, WHO Bangladesh for his thorough review of the draft manuscript and valuable inputs to this. Finally, we would like to extend our sincere gratitude to the Field Supervisors and Data Collectors for their contributions throughout the qualitative and quantitative data collection.

\section{About this supplement}

This article has been published as part of Human Resources for Health Volume 19, Supplement 1 2021: Countries' experiences on implementing WISN methodology for health workforce planning and estimation. The full contents of the supplement are available at https://human-resourceshealth.biomedcentral. com/articles/supplements/volume-19-supplement-1.

\section{Authors' contributions}

MN, TZ and VdoC conceived and designed the study. MN wrote the first draft of the manuscript. TJ, SNBKT and MN carried out the data analyses of the manuscript. MN, TZ, VdoC and TJ provided substantial technical inputs in the inception phase and throughout the study process. MN, TZ, SA, VdOC and TJ thoroughly reviewed the manuscript and contributed substantially with the necessary revision. MN and TZ again reviewed the manuscript and prepared for the final submission. All authors read and approved the final manuscript.

\section{Funding}

Publication cost is funded by the World Health Organization.

\section{Availability of data and materials}

The datasets generated and/or analyzed during the current study are not publicly available due to joint ownership of the data, but they are available from the corresponding author on reasonable request. Data may be obtained from the World Health Organization Bangladesh Country Office on reasonable request (Focal Point: NPO-HRH: nuruzzamanm@who.int).

\section{Declarations}

Ethics approval and consent to participate

Ethical approval for this study was secured from the Institutional Review Board of BRAC James P Grant School of Public Health, BRAC University. Formal consent was taken from each of the respondents before conducting the interview for data collection from them.

\section{Consent for publication}

Not applicable.

\section{Competing interests}

None declared.

\section{Author details}

${ }^{1}$ Human Resources for Health, WHO Bangladesh, Dhaka, Bangladesh. ${ }^{2}$ Human Resources for Health, WHO South-East Asia Regional Office, Delhi, India. ${ }^{3}$ Health Financing and Governance, WHO South-East Asia Regional Office, Delhi, India. ${ }^{4}$ Health Services Division, Ministry of Health and Family Welfare, Dhaka, Bangladesh. ${ }^{5}$ BRAC James P Grant School of Public Health, BRAC Uni-

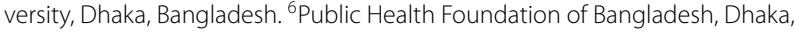
Bangladesh.

Received: 3 December 2021 Accepted: 6 December 2021

Published: 28 January 2022

\section{References}

1. World Health Organization, The World Health Report 2006: working together for health, Geneva, 2006.

2. Bangladesh Health Watch, Health Workforce in Bangladesh Who constitute the health systems The State of Health in Bangladesh-2007, Dhaka: James P Grant School of Public Health, BRAC University, 2008.

3. World Health Organization, Global Strategy on Human Resources for Health: Workforce 2030, Geneva: 2016.

4. WHO South East Asia Regional Office. "Decade for health workforce strengthening in the South-East Asia Region 2015-2024 Mid-term review of progress", New Delhi: WHO South East Asia Regional Office, 2020. https://apps.who.int/iris/handle/10665/334226 (Access on 22 November 2020).

5. Ahmed SM, Hossain MA, RajaChowdhury AM, et al. The health workforce crisis in Bangladesh: shortage, inappropriate skill-mix and inequitable distribution. Hum Resour Health. 2011;9(1):3. https://doi.org/10.1186/ 1478-4491-9-3.

6. Ahmed SM, Alam BB, Anwar I, Begum T, Huque R, Khan JAM, Nababan H. Bangladesh Health System Review, Dhaka: World Health Organization, 2015. http://apps.who.int/iris/bitstream/handle/10665/208214/97892 90617051_eng.pdf?sequence=1\&isAllowed=y (Assessed 23 Nov 2020).

7. Government of Bangladesh, "Bangladesh Essential Health Service Package (ESP).," Ministry of Health and Family Welfare, Dhaka, 2016. http:// www.mohfw.gov.bd/index.php?option=com_docman\&task=doc_ download\&gid $=9484 \&$ lang $=$ en (Accessed on 24 February 2021)

8. Government of Bangladesh, Standard Set-up of Manpower for 10-, 20-, 31-, 50-, 100-,150- 200-, 500-bed hospitals, Dhaka: Ministry of Public Administration (in Bangla), 2008.

9. Namaganda G, Oketcho V, Maniple E, Viadro C. Making the transition to workload-based staffing: using the Workload Indicators of Staffing Need method in Uganda. Human Resour Health. 2015;13(1):89. https://doi.org/ 10.1186/s12960-015-0066-7.

10. Government of Bangladesh, Bangladesh Health Workforce Strategy2015, Dhaka: Ministry of Health and Family Welfare, 2015.

11. World Health Organization, WISN: Workload Indicators of Staffing Need. User's manual, Geneva: 2010. https://www.who.int/hrh/resources/WISN_ Eng_UsersManual.pdf?ua=1 (Accessed on 23 November 2020.

12. Shipp PJ. "Workload Indicators of STaffing Need (WISN): a manual for implementation". World Health Organization. 1998. https://apps.who.int/ iris/handle/10665/64011. [Accessed 17 March 2020].

13. Government of Bangladesh. "Report on Analysis of human resources for health in Bangladesh and determination of their supply and demand." Human Resources Development Unit, Ministry of Health and Family Welfare, Dhaka, 2011

14. Government of Bangladesh, "Responsibilities of the Ministry of Public Administration", Dhaka: Ministry of Public Administration, 2016. https:// mof.portal.gov.bd/sites/default/files/files/mof.portal.gov.bd/page/3ef11 
11d_f0d6_41ea_aca9_6afb61228825/G-3_03_07_Public\%20Admn_Engli sh.pdf (Accessed on 20 August 2020.

15. Ritchie J, Lewis J. Elam G. In Ritchie J, Lewis J. (eds). Qualitative research practice: a guide for social science students and researchers, California: SAGE Publications, 2003.

16. Government of Bangladesh, Health Bulletin 2016. Dhaka: Directorate General of Health Services, 2016. https://dghs.gov.bd/images/docs/Publi caations/HB\%202016\%20_2nd_edition_13_01_17.pdf (Accessed on 23 November 2020).

17. Greenglass ER, Burke RJ, Moore KA. Reactions to increased workload: effects on professional efficacy of nurses. Appl Psychol. 2003;52(4):58097. https://doi.org/10.1111/1464-0597.00152.

18. Ly A, Kouanda S, Ridde V. Nursing and midwife staffing needs in maternity wards in Burkina Faso referral hospitals. Hum Resour Health. 2014. https://doi.org/10.1186/1478-4491-12-S1-S8.

19. Nayebi BA, Mohebbifar R, Azimian J, Rafiei S. Estimating nursing staff requirement in an emergency department of a general training hospital: application of Workload Indicators of Staffing Need (WISN). Int J Healthcare Manag. 2019;12(1):54-9. https://doi.org/10.1080/20479700.2017. 1390182.

20. Burmen B, Owuor N, Mitei P. An assessment of staffing needs at a HIV clinic in a Western Kenya using the WHO workload indicators of staffing need WISN, 2011. Hum Resour Health. 2017;15:9. https://doi.org/10.1186/ s12960-017-0186-3.

21. McQuide PA, Kolehmainen-Aitken RL, Foster N. Applying the workload indicators of staffing need (WISN) method in Namibia: challenges and implications for human resources for health policy. Hum Resour Health, 2013;11(64).

22. Mendoza Aldana J, Piechulek H, al-Sabir A. Client satisfaction and quality of health care in rural Bangladesh. Bulletin of the World Health Organization, 2001;79(6): 512-517. https://www.ncbi.nlm.nih.gov/pmc/articles/ PMC2566452/ Accessed on 10 November 2020.

23. Ogden J, Bavalia K, Bull M, Frankum S, Goldie C, Gosslau M, Jones A, Kumar S, Vasant K. "I want more time with my doctor": a quantitative study of time and the consultation. Fam Pract. 2004;21(5):479-83. https:// doi.org/10.1093/fampra/cmh502 (PMID: 15367468).

24. Joarder T, Mahmud I, Sarker M, et al. Development and validation of a structured observation scale to measure responsiveness of physicians in rural Bangladesh. BMC Health Serv Res. 2017;17:753. https://doi.org/10. 1186/s12913-017-2722-1.

25. Irving $G$, Neves AL, Dambha-Miller $H$, et al. International variations in primary care physician consultation time: a systematic review of 67 countries. BMJ Open. 2017;7: e017902. https://doi.org/10.1136/bmjop en-2017-017902.

26. Joarder T, Tune SN, Nuruzzaman $M$, et al. Assessment of staffing needs for physicians and nurses at Upazila health complexes in Bangladesh using WHO workload indicators of staffing need (WISN). BMJ Open. 2020;10:e035183. https://doi.org/10.1136/bmjopen-2019-035183.

27. "Workload and Staffing Needs Assessment at Public Sector Health Care Facilities in Bangladesh," MaMoni-Health Systems Strengthening (HSS), United States Agency for International development, Dhaka, Bangladesh, 2017-2018.

28. Brain Storming Session of Organization, HRH and Service Delivery on 29-30 November 2019, Dhaka: Government of Bangladesh, Directorate General of Health Services (Memo No 6399, 17/11/2019), 2019.

29. "Bangladesh Preparedness and Response Plan for COVID-19," Health Services Division, Ministry of Health \& Family Welfare, Dhaka, 2020.

30. Zaman RU, Khaled A, Sabur MA, et al. Experiences of a new cadre of midwives in Bangladesh: findings from a mixed method study. Hum Resour Health. 2020. https://doi.org/10.1186/s12960-020-00505-8.

\section{Publisher's Note}

Springer Nature remains neutral with regard to jurisdictional claims in published maps and institutional affiliations.

Ready to submit your research? Choose BMC and benefit from:

- fast, convenient online submission

- thorough peer review by experienced researchers in your field

- rapid publication on acceptance

- support for research data, including large and complex data types

- gold Open Access which fosters wider collaboration and increased citations

- maximum visibility for your research: over 100M website views per year

At BMC, research is always in progress.

Learn more biomedcentral.com/submissions 